\title{
Epidemiological Characteristics of Spinal Cord Injury in Northwest China: a single hospital-based study
}

\author{
ZhiMeng Wang \\ honghui hospital \\ Peng Zou \\ honghui hospital \\ Jun-Song Yang \\ honghui Hospital \\ Ting-ting Liu \\ northwest women's and children's hospital \\ Leilei Song \\ honghui Hospital \\ Yao Lu \\ honghui Hospital \\ Hao Guo \\ honghui hospital \\ Yuan-Tin Zhao \\ honghui hospital \\ Tuan-Jiang Liu \\ honghui hospital \\ Ding-Jun Hao ( $\sim$ dingjun.hao@qq.com ) \\ Honghui Hospital, Xi'an Jiaotong University
}

\section{Research article}

Keywords: Spinal injuries, Epidemiology, Northwest China, Retrospective study, Investigation

Posted Date: April 20th, 2020

DOI: https://doi.org/10.21203/rs.3.rs-21466/v1

License: (c) (1) This work is licensed under a Creative Commons Attribution 4.0 International License.

Read Full License 
Version of Record: A version of this preprint was published at Journal of Orthopaedic Surgery and Research on June 9th, 2020. See the published version at https://doi.org/10.1186/s13018-020-01729-z. 


\section{Abstract}

Background: The northwest is relatively backward economically. Unfortunately, the epidemiological characteristics of SCl in Northwest China are rarely reported.

Methods: The SCl epidemiological survey software independently developed was used to sort out the data of patients treated with SCI from 2014 to 2018. Variables included age, sex, cause of injury, combined injury, severity of injury, ASIA scale, surgical treatment, complications, and rehabilitation.

Results: The enrolled 3487 patients were with a male to female ratio of 2.57:1 and an age of $39.50 \pm 11.20$ years. SCl in $94.03 \%$ of patients was caused by falls and MCVs, which were the primary etiologies of SCI. There were 1786 patients, accounting for $51.22 \%$, with other injuries. Asia D scale patients accounted for $41.12 \%$. During hospitalization, pulmonary infection was the most common complication (437 cases, $32.59 \%$ ), followed by hyponatremia (326 cases, $24.31 \%$ ), bedsore (219 cases, $16.33 \%)$, urinary tract infection (168 cases, $12.53 \%$ ), deep vein thrombosis (157 cases, $11.71 \%$ ) and others (34 cases, $2.53 \%$ ). Only 528 patients $(15.14 \%)$ received long-term rehabilitation treatment.

Conclusion: The incidence of $\mathrm{SCl}$ in northwest China was on the rise with higher proportion in males, the MCVs and fall were the primary leading causes of injuries. The occupations most at risk from $\mathrm{SCl}$ are peasantries and workers. Pulmonary infection rate was the most common complication during hospitalization. Patients over the age of 50 , especially the elderly, should pay attention to preventing falls and osteoporosis. Young people should pay attention to safe production and avoid falling from high places and falling objects.

\section{Introduction}

Spinal cord injury (SCl) not only causes serious functional and family financial burdens, but also poses a series of problems for patients' mental health and social stability(1). SCl is considered to be a major public health matter worldly, and the incidence of spinal cord injury vary widely around the world. $\mathrm{SCl}$ is considered a worldwide public health problem, but its incidence varies greatly from region to region(2). The average annual incidence of $\mathrm{SCl}$ in developed countries ranges from 10.4 per million to 83 per million $(3,4)$. In developing countries, SCl had a high incidence of 25.5 per million per year(5). Under the background that there is no effective rehabilitation method for spinal cord injury, primary prevention is particularly important.

There are few studies reported the epidemiological characteristics of SCl based on hospital in China, such as Beijing(6),Shanghai(7),Guangdong(8) and Chongqing(9). In terms of epidemiology, each region has its own characteristics in the occurrence of $\mathrm{SCl}$, so it is of great significance to carry out epidemiological research on $\mathrm{SCl}$ at the local population level. However, we find that all these cities are highly developed and their medical care is at the forefront of China. The northwest is relatively backward economically, whose epidemiological characteristics of $\mathrm{SCl}$ are rarely reported. The study was aimed to investigate the epidemiological characteristics of patients with SCl in the backward areas of Northwest China; and 
facilitate establishing the optimal allocation of medical resources and reducing the financial and social burdens.

\section{Materials And Methods}

As the tertiary trauma center in Northwest China, our hospital has collected the largest sample size of spinal cord injury patients. This study was approved by the Ethics Committee of our hospital. The inclusion criteria were patients with traumatic $\mathrm{SCl}$ or cauda equina injuries who were admitted to our hospital between 2014 and 2018. Patients with the following conditions were excluded from the study:

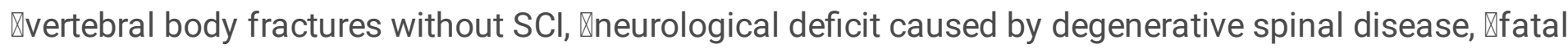
injuries, 区the medical records was incomplete. The SCl epidemiological survey software independently developed was used to sort out the data of patients. The variables studied were associated with the social demographic profile of patients (name, age, sex and occupation). Medical records consist of the cause, fracture part, associated injury and level of injury, which were determined by physical and radiographic examinations. Neurological levels of $\mathrm{SCl}$ were classified using the American Spinal Injury Association (ASIA) impairment scale. In addition, the treatment methods and complications during hospitalization were also documented.

The SCl epidemiological survey software independently developed was used to sort out the data of patients. The demographic information of patients (age, gender and occupation), the cause of injury and neurological levels were summarized. Neurological function were evaluated by the ASIA impairment scale. In addition, the treatment methods and complications during hospitalization were also included.

\section{Statistical analysis}

Mean values are presented as the mean \pm SD. Analysis of variance (ANOVA) and Chi-square test have been used to find the significance of study parameters on enumeration data and categorical scale between groups respectively. A value of $p<.05$ was considered statistical signifcance. All statistical analyses were performed using Statistical Product and Service Solution Version 19.0 (SPSS, Inc, Chicago, IL, USA)

\section{Results}

\section{General demographic characteristics of SCI patients from 2014 to 2018}

A total of 3487 patients with SCl were identified in this study, the number of SCl patients is increasing year by year (Fig. 1). As shows in Table 1, the general demographic characteristics of SCl patients. Of the 3487 individuals with SCl, 2509 were male $(71.95 \%)$ and 978(28.05\%) were female, and male to female was 2.57:1. The patients' ages ranged from 18 to 87 years, with a mean age of $39.50 \pm 11.20$ years, males $36.60 \pm 12.40$ years, females $42.80 \pm 11.80$ years). 
Table 1

demographic information, etiology of patients with SCI from 2014 to 2018

\begin{tabular}{|c|c|c|c|c|c|c|}
\hline Years & 2014 & 2015 & 2016 & 2017 & 2018 & Total \\
\hline Age & 2 & 0 & 1 & 1 & 5 & 9 \\
\hline $0-20$ & 86 & 79 & 93 & 117 & 146 & 521 \\
\hline $20-29$ & 335 & 274 & 361 & 344 & 385 & 1699 \\
\hline $30-39$ & 114 & 107 & 143 & 198 & 228 & 790 \\
\hline $40-49$ & 67 & 85 & 70 & 83 & 109 & 414 \\
\hline $50-59$ & 13 & 5 & 8 & 11 & 17 & 54 \\
\hline \multicolumn{7}{|l|}{$\geq 60$} \\
\hline Gender & 446 & 413 & 504 & 533 & 613 & 2509 \\
\hline Male & 171 & 137 & 172 & 221 & 277 & 978 \\
\hline \multicolumn{7}{|l|}{ Female } \\
\hline Occupation & 387 & 354 & 401 & 442 & 491 & 2075 \\
\hline Farmer & 155 & 138 & 179 & 213 & 258 & 943 \\
\hline Worker & 43 & 37 & 58 & 61 & 68 & 267 \\
\hline Government-offices & 8 & 6 & 8 & 15 & 36 & 73 \\
\hline Retired & 15 & 10 & 18 & 13 & 19 & 75 \\
\hline Students & 9 & 5 & 12 & 10 & 18 & 54 \\
\hline \multicolumn{7}{|l|}{ Other* } \\
\hline Etiology & 301 & 277 & 328 & 358 & 401 & 1665 \\
\hline Low fall & 252 & 223 & 241 & 259 & 326 & 1301 \\
\hline High Fall & 39 & 41 & 72 & 77 & 84 & 313 \\
\hline MVCs & 15 & 4 & 24 & 47 & 63 & 153 \\
\hline Fall objects & 8 & 4 & 6 & 9 & 13 & 40 \\
\hline Sports & 2 & 1 & 5 & 4 & 3 & 15 \\
\hline \multicolumn{7}{|l|}{ Violence } \\
\hline Total number & 617 & 550 & 676 & 754 & 890 & 3487 \\
\hline \multicolumn{7}{|c|}{ Other* included unemployed individuals and self-employed individuals } \\
\hline
\end{tabular}




\section{Injury etiologies and age distribution of patients with $\mathrm{SCI}$}

In this study, the primary cause of SCI was fall (low falls $47.75 \%$, high falls $37.31 \%$ ), followed by traffic accidents $(8.98 \%)$, falling objects $(4.39 \%)$. Furthermore, there were several uncommon causes, for instance sports injuries $(1.15 \%)$, violence injuries $(0.43 \%)$. The peak age distribution of patients with $\mathrm{SCl}$ was $30-49$ years old, accounting for $80.99 \%$ of the total patients, and the incidence was negatively correlated with age. There are differences in the injury etiologies among different age groups (Table 2). The common etiologies in the 30-39 age group were fall (low fall and high fall) and motor vehicle collisions (MCVs). However, low fall was the primary cause of SCl in the 60-year-old group, which changed to motor injuries for the patients between the ages of 20 and 29.

Table 2

Analysis of the etiologies and age distribution among the spinal cord injury $(\mathrm{SCl})$ patients

\begin{tabular}{|c|c|c|}
\hline \multirow[t]{2}{*}{ Etiologies } & Age & \multirow[t]{2}{*}{ Total } \\
\hline & $0-2020-29 \quad 30-39 \quad 40-4950-59 \geq 60$ & \\
\hline Low fall & 021373342026237 & 1665 \\
\hline High fall & 1199759282537 & 1301 \\
\hline MVCs & 475132583410 & 313 \\
\hline Falling objects & 096121620 & 153 \\
\hline Sports & 32110600 & 40 \\
\hline Violence & 144330 & 15 \\
\hline
\end{tabular}

\section{Level injury and associated injuries}

As shows in Fig. 2, the fracture took on a bimodal distribution. The first peak is cervical region, especially C4-C6, secondly is thoracolumbar region, especially T11-L3(34.82\% and 38.40\%, respectively).In this study, 1786 patients (51.22\%) were complicated with other injuries, including craniocerebral injury $(198,11.09 \%)$, frontofacial injury $(407,22.79 \%)$, chest and abdominal injury $(359,20.10 \%)$, pelvic injury $(258,14.45 \%)$ and limb fracture $(564,31.58 \%)$.

\section{ASIA impairment scale}

According to the ASIA impairment scale, the proportion of grade A, B, C and D injuries was $747(21.42 \%)$, $688(19.73 \%), 618(17.72 \%)$ and $1434(41.12 \%)$, respectively. The severity of injury caused by different causes, ASIA A grade patients were mainly by MCVs and high fall, B-C grades were mainly by low falls (Table 3). The different injury sites caused different injury grade. Injuries in the cervical cord and lumbar 
cord, which was widely distributed in ASIA A-D, the thoracic cord injuries were mostly ASIA A-B, moreover, sacral cord injury mainly ASIA D. (Table 4).

Table 3

Comparison of causes of injury in different degrees of spinal cord injury

\begin{tabular}{|ll|}
\hline Etiologies & ASIA scale \\
\cline { 2 - 2 } & $\mathbf{A}(\%) \mathbf{B}(\%) \mathrm{C}(\%) \mathbf{D}(\%)$ \\
\hline Low fall & $129(17.27) 267(38.81) 293(47.41)$ 976(68.06) \\
\hline High fall & $410(54.89) 277(37.08) 249(40.29) 365(25.45)$ \\
\hline MVCs & $136(18.21) 78(11.34) 51(8.25) 48(3.35)$ \\
\hline Falling objects & $57(7.63) 58(8.43) 14(2.27) 24(1.67)$ \\
\hline Sports & $8(1.07) 5(7.27) 7(1.13) 20(1.39)$ \\
\hline Violence & $7(0.94) 3(4.36) 4(0.65) 1(0.07)$ \\
\hline
\end{tabular}

Table 4

Analysis of the degrees and segment of the injury among the SCl patients

\begin{tabular}{|ll|}
\hline ASIA scale & The level of injury \\
\cline { 2 - 3 } & Cervical cord(\%) Thoracic cord(\%) Lumbar cord(\%) Sacral cord(\%) \\
\hline A & $516(31.29) 267(30.20) 96(10.29) 0(0.00)$ \\
\hline B & $249(15.10) 277(31.33) 198(21.22) 0(0.00)$ \\
\hline C & $121(7.33) 78(8.82) 167(17.90) 0(0.00)$ \\
\hline D & $763(46.27) 0(0.00) 472(50.59) 21(100)$ \\
\hline
\end{tabular}

\section{Treatment of SCl and Clinical Complications}

There were 2,763 patients $(79.24 \%)$ who received surgical treatment and 724 patients $(20.76 \%)$ who were conservatively treated. The hospitalization of patients with SCI was 1 to 378 days, with an average of 17.50 days. During the hospitalization period, a total of 1341 patients had complications, the incidence rate was $38.46 \%$ (Table 5). Of all the complications, pulmonary infection was the most common (437, $32.59 \%)$, followed by hyponatremia $(326,24.31 \%)$, bedsore $(219,16.33 \%)$, urinary tract infection $(168$, $12.53 \%)$, deep venous thrombosis $(157,11.71 \%)$ and others $(34,2.53 \%)$. 
Table 5

Clinical Complications During the hospitalization

\begin{tabular}{|ll|}
\hline Complication & Number(\%) \\
\hline Pulmonary infection & $437(32.59 \%)$ \\
\hline Hyponatremia & $326(24.31)$ \\
\hline Bedsore & $219(16.33)$ \\
\hline Urinary tract infection & $168(12.53)$ \\
\hline Deep venous thrombosis & $157(11.71)$ \\
\hline Others & $34(2.53)$ \\
\hline
\end{tabular}

\section{Discussion}

Compared with other areas of China, there are several unique characteristics at northwest. The northwest is located in the hinterland of mainland China, mostly plateaus and basins. Compared with the economically developed areas in the eastern coastal areas, the level of economic and political are poor. In addition, the Northwest China is dominated by agriculture, with farmers accounting for the majority of the labor force, accompanied by lower levels of health insurance, education and lower household incomes. Our Hospital is the tertiary trauma center located in Xi'an, which is the economic and cultural centers of the Northwest China. Therefore, the SCI patients admitted by our hospital can objectively represent the epidemiological characteristics of SCl patients in northwest China.

Based on the epidemiological characteristics of $\mathrm{SCl}$ in our hospital over the past five years, we found that $\mathrm{SCl}$ not only causes abnormal sensory and motor functions below the injury level, but also causes many important organ dysfunction, including respiratory system, urinary system, digestive system and so on, which adds extra hospital costs. Thus, $\mathrm{SCl}$ should not be neglected in Northwest China, the prevention of spinal cord injury is particularly important, comprehensive and detailed epidemiological investigation is the basis of effective prevention countermeasures.

In this investigation, the male to female ration of $\mathrm{SCl}$ was $2.57: 1$, which was distinct with Beijing, Shanghai, Guangdong, Chongqing ,Anhui and Heilongjiang(6-11). This may have something to do with the different responsibilities and social division of labor between men and women in different provinces in China. Considering the reasons, the patients mainly come from the Northwest region, which is economically backward and resource-poor. Women's exposure to high-risk industries, such as construction and transportation, increases. At the same time, women are prone to osteoporotic fracture, which increases the proportion of women in SCl patients, there have the same true in South Africa (12). 
The highest proportion of SCl in Northwest China was noted in the 30-49 years. In traditional Chinese culture, it is a unshirkable responsibility of the young and middle-age to support their parents and raise their children. Because of the large financial responsibility, they need to take a huge risk to raise their families. Meanwhile, the roads in northwestern China are rugged and complicated. Various reasons increase the possibility that they suffer from work-related $\mathrm{SCl}$, making people aged 30-49 a high-risk group. China's aging population is increasing, with more elderly people suffering from SCl. For the elderly patients, $\mathrm{SCl}$ may coexist with degenerative spine disease and/or osteoporotic compression fractures. Therefore, attention should be paid to the needs of the elderly in SCl rehabilitation(13). In this study, the proportion of farmers and laborers was as high as $59.51 \%$ and $27.04 \%$, respectively. It is different with previous reports in Guangdong(8), Turkish(14) and México(15). Differences may rooted from the diversity of economic and political environments. Northwest China has a high proportion of the population engaged in agriculture-related occupations; and the probability of $\mathrm{SCl}$ occurrence is higher than that of any other occupation.

The causes of SCI include, falls (high fall and low fall), MVCs, fall objects, sports and violent injuries. there are also some differences among countries or regions. We found that falling (high fall and low fall) was the mainly cause of $\mathrm{SCl}$, followed by MVCs, which happened at almost all ages. An epidemiological survey in Canada in 2006 showed that MVCs were the main cause of SCl, but the fall became the mainly cause in $2009(16,17)$. The incidence of violence in the various countries or regions were also distinct, the cause of this injury is only $0.40 \%$ in Beijing(6), while $11.90 \%$ in Brazil(18). Like violent injuries, gunshot wounds were rare in our country, mainly because the state strictly manages social security and strictly controls guns. Similar to other developing countries, the per capita car ownership in China is increasing, meanwhile, the improvement of transport safety measures and the increase in traffic safety awareness, those made the proportion of $\mathrm{SCl}$ related to traffic injuries has declined.

Similar to the finding of previous studies $(9,19)$, the damaged region in this study showed a bimodal distribution, with C4-C6 and T11-L3 being the most common levels of injury; and the incidence of cervical $\mathrm{SCl}$ was the highest (47.29\%). Additionally, we also found an association between the severity of spinal cord injury and the cause of the injury. MCVs and high fall injuries mostly led to complete SCl, mainly grade A. However, the grade D spinal cord injuries are mostly caused by low falls, which are mostly manifested as incomplete SCl. Williams et al(20) and Thietje et al(21) reported that patients with grade A spinal cord injuries are more likely to suffer from depressive disorders and suicide, and doctors and their families should give more care and help to prevent the occurrence of suicide caused by depression.

The results of this study showed that there were 1341 patients with complications, the incidence rate was $36.49 \%$. Of all the complications, respiratory diseases were the most common (30.7\%). This is associated with long-term bed rest, basic lung disease caused by smoking before incidence and rib fractures. Cervical spinal cord injury can reflect the function of diaphragm or intercostal muscle, weaken the strength of respiration and cough, and the sputum was not easy to cough out, which were also related to respiratory complications(22). The higher the level of $\mathrm{SCl}$, the higher the incidence of pulmonary infection. The incidence of pulmonary infection can reach more than $90 \%$ when the $\mathrm{SCl}$ located above the 
level of $\mathrm{C} 5$ and causing diaphragm movement dysfunction (23). The results also showed that the average hospitalization time of $\mathrm{SCl}$ patients was 10.70 days, the longest was 94 days, and the hospitalization cost was 4,352 yuan to 45,6320 yuan (average 37,850 yuan). It is pointed out that the hospitalization period of $\mathrm{SCl}$ patients is long, the cost is high, and the income of most patients is low and the ability to pay is limited, so it is difficult to get comprehensive and effective treatment. However, it is a pity that there were only $15.14 \%$ of the SCl patients received rehabilitation. Although this may be related to the low overall $\mathrm{SCl}$ rehabilitation level in Northwest China, it also reflects our insufficient attention to $\mathrm{SCl}$ postoperative rehabilitation.

Our study has several limitations:(1) This study is a hospital-based descriptive SCl study that only identified a small proportion of all SCI patients in Northwest China. (2) We only collected the information who admitted to hospital with $\mathrm{SCl}$, leaved out the information on patients who died in hospitals before admission. (3) The number and cycle of studies subjects were restively limited. (4) We lack systematic training and there are omissions in the process of collecting data.

\section{Conclusion}

Through the investigation and analysis of the epidemiological characteristics of $\mathrm{SCl}$ in Northwest China, it is suggested that the understanding of $\mathrm{SCl}$ should be improved. We need to strengthen safety education and protection for high-risk groups to reduce the incidence of catastrophic spinal cord injuries. Respiratory complications are important factors leading to death after $\mathrm{SCl}$, especially when the injury is located in the cervical spinal cord. Meanwhile, the significance of the rehabilitation of spinal cord injury should be addressed.

\section{Abbreviations}

Spinal cord injury (SCl)

American Spinal Injury Association (ASIA)

Analysis of variance (ANOVA)

motor vehicle collisions (MCVs).

\section{Declarations}

Ethics approval and consent to participate: The study was approved by the ethical committee of Honghui Hospital, Xi'an Jiaotong University. The patient gave written consent to for research applications of their clinical data. The patient data was anonymised in this study.

Consent for publication: Consent to publish was obtained from the patients detailed in this study. 
Availability of data and materials: The datasets generated during the current study are public at the email dingjun.hao@qq.com.

Competing interests: The authors declare no conflict of interests.

Funding: This work was supported by the key project of national natural science foundation of China (No. 81830077 for Ding-Jun Hao) and the Project of Science and Technology Department of Shaanxi Province (2017ZDXM-SF-009;2019JQ-976).

Authors' contributions: Conceived and designed the experiments: Hao DJ and Yang JS. Performed the experiments: Zou P and Song LL. Collected the data:Zou P Lu Y, Guo H, Zhao YT and Liu TJ. Contributed reagents/materials/analysis tools: Liu TT. Wrote the paper: Yang JS and Wang ZM.

Acknowledgements: We acknowledge the financial support received from the key project of national natural science foundation of China (No. 81830077 for Ding-Jun Hao) and the Project of Science and Technology Department of Shaanxi Province (2017ZDXM-SF-009;2019JQ-976) in the language polishing of manuscripts.

\section{References}

1. Mirzaeva L, Gilhus NE, Lobzin S, Rekand T. Incidence of adult traumatic spinal cord injury in Saint Petersburg, Russia. Spinal cord. 2019;57(8):692-9.

2. Hagen EM, Rekand T, Gilhus NE, Gronning M. Traumatic spinal cord injuries-incidence, mechanisms and course. Tidsskrift for den Norske laegeforening : tidsskrift for praktisk medicin, ny raekke. 2012;132(7):831-7.

3. Wyndaele M, Wyndaele JJ. Incidence, prevalence and epidemiology of spinal cord injury: what learns a worldwide literature survey? Spinal Cord. 2006;44(9):523-9.

4. Skolasky RL, Thorpe RJ, Jr., Wegener ST, Riley LH, 3rd. Complications and mortality in cervical spine surgery: racial differences. Spine. 2014;39(18):1506-12.

5. Rahimi-Movaghar V, Sayyah MK, Akbari H, Khorramirouz R, Rasouli MR, Moradi-Lakeh M, et al. Epidemiology of traumatic spinal cord injury in developing countries: a systematic review. Neuroepidemiology. 2013;41(2):65-85.

6. Li J, Liu G, Zheng Y, Hao C, Zhang Y, Wei B, et al. The epidemiological survey of acute traumatic spinal cord injury (ATSCI) of 2002 in Beijing municipality. Spinal cord. 2011;49(7):777-82.

7. Chang FS, Zhang Q, Sun M, Yu HJ, Hu LJ, Wu JH, et al. Epidemiological study of Spinal Cord Injury individuals from halfway houses in Shanghai, China. The journal of spinal cord medicine. 2018;41(4):450-8.

8. Yang R, Guo L, Huang L, Wang P, Tang Y, Ye J, et al. Epidemiological Characteristics of Traumatic Spinal Cord Injury in Guangdong, China. Spine. 2017;42(9):E555-e61. 
9. Ning GZ, Mu ZP, Shangguan L, Tang Y, Li CQ, Zhang ZF, et al. Epidemiological features of traumatic spinal cord injury in Chongqing, China. The journal of spinal cord medicine. 2016;39(4):455-60.

10. Wang HF, Yin ZS, Chen Y, Duan ZH, Hou S, He J. Epidemiological features of traumatic spinal cord injury in Anhui Province, China. Spinal cord. 2013;51(1):20-2.

11. Chen R, Liu X, Han S, Dong D, Wang $Y$, Zhang $H$, et al. Current epidemiological profile and features of traumatic spinal cord injury in Heilongjiang province, Northeast China: implications for monitoring and control. Spinal cord. 2017;55(4):399-404.

12. Pefile N, Mothabeng JD, Naidoo S. Profile of patients with spinal cord injuries in Kwazulu-Natal, South Africa: Implicactions for vocational rehabilitation. The journal of spinal cord medicine. 2018:110.

13. Kudo D, Miyakoshi N, Hongo M, Kasukawa Y, Ishikawa Y, Ishikawa N, et al. An epidemiological study of traumatic spinal cord injuries in the fastest aging area in Japan. Spinal cord. 2019;57(6):509-15.

14. Guzelkucuk U, Kesikburun S, Demir Y, Aras B, Ozyoruk E, Yilmaz B, et al. Demographic and clinical characteristics of patients with traumatic cervical spinal cord injury: a Turkish hospital-based study. Spinal cord. 2015;53(6):441-5.

15. Zarate-Kalfopulos B, Jimenez-Gonzalez A, Reyes-Sanchez A, Robles-Ortiz R, Cabrera-Aldana EE, Rosales-Olivarez LM. Demographic and clinical characteristics of patients with spinal cord injury: a single hospital-based study. Spinal cord. 2016;54(11):1016-9.

16. Pickett GE, Campos-Benitez M, Keller JL, Duggal N. Epidemiology of traumatic spinal cord injury in Canada. Spine. 2006;31(7):799-805.

17. Kattail D, Furlan JC, Fehlings MG. Epidemiology and clinical outcomes of acute spine trauma and spinal cord injury: experience from a specialized spine trauma center in Canada in comparison with a large national registry. The Journal of trauma. 2009;67(5):936-43.

18. Leal-Filho MB, Borges G, Almeida BR, Aguiar Ade A, Vieira MA, Dantas Kda S, et al. Spinal cord injury: epidemiological study of 386 cases with emphasis on those patients admitted more than four hours after the trauma. Arquivos de neuro-psiquiatria. 2008;66(2b):365-8.

19. Fredo HL, Rizvi SA, Lied B, Ronning P, Helseth E. The epidemiology of traumatic cervical spine fractures: a prospective population study from Norway. Scandinavian journal of trauma, resuscitation and emergency medicine. 2012;20:85.

20. Williams RT, Wilson CS, Heinemann AW, Lazowski LE, Fann JR, Bombardier CH. Identifying depression severity risk factors in persons with traumatic spinal cord injury. Rehabilitation psychology. 2014;59(1):50-6.

21. Thietje R, Pouw MH, Schulz AP, Kienast B, Hirschfeld S. Mortality in patients with traumatic spinal cord injury: descriptive analysis of 62 deceased subjects. The journal of spinal cord medicine. 2011;34(5):482-7.

22. Jiang F, Jaja BNR, Kurpad SN, Badhiwala JH, Aarabi B, Grossman RG, et al. Acute Adverse Events After Spinal Cord Injury and Their Relationship to Long-term Neurologic and Functional Outcomes: 
Analysis From the North American Clinical Trials Network for Spinal Cord Injury. Critical care medicine. 2019.

23. Fehlings MG, Vaccaro A, Wilson JR, Singh A, D WC, Harrop JS, et al. Early versus delayed decompression for traumatic cervical spinal cord injury: results of the Surgical Timing in Acute Spinal Cord Injury Study (STASCIS). PloS one. 2012;7(2):e32037.

Figures

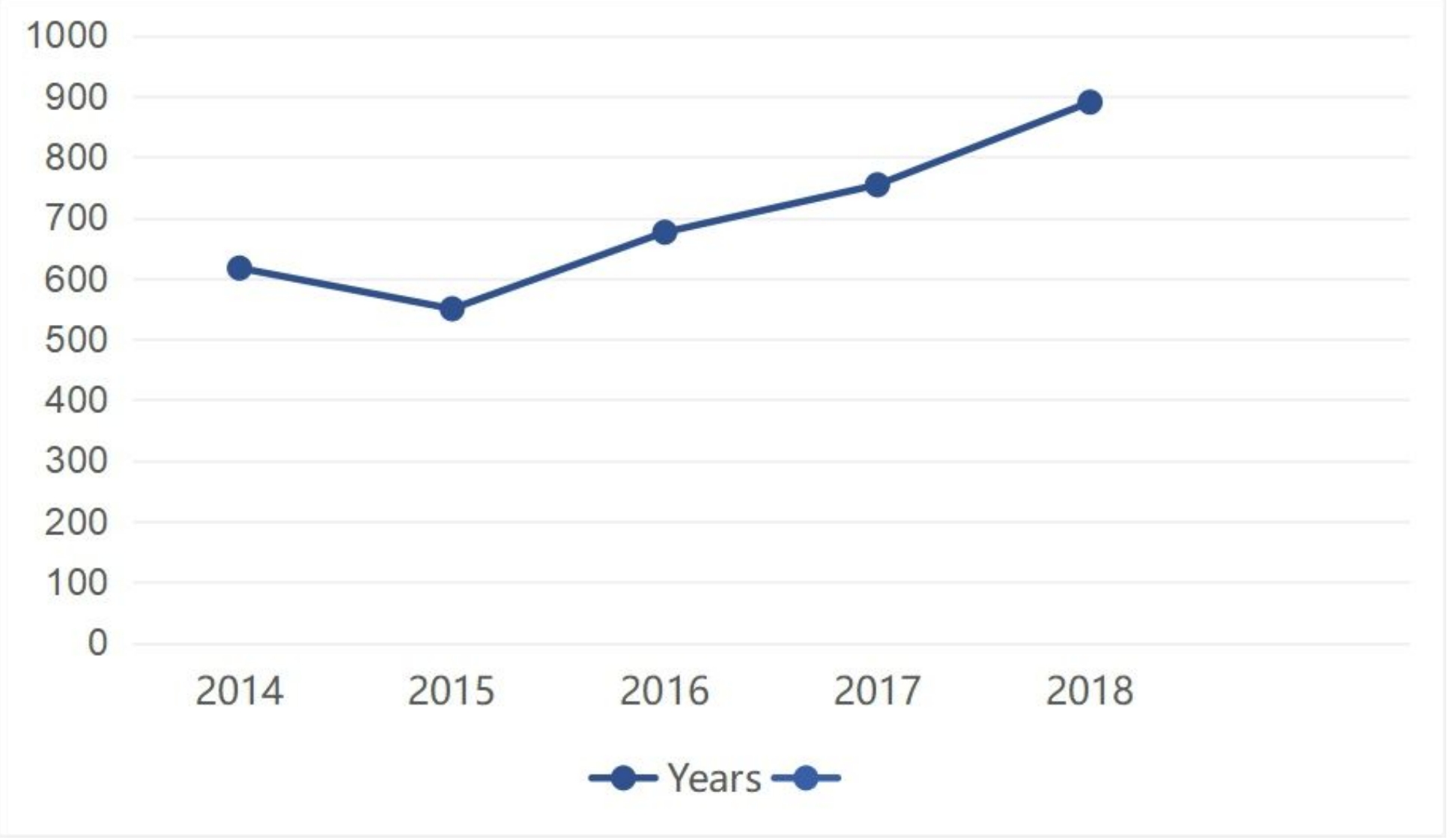

\section{Figure 1}

The trend of SCI patients during 2014-2018 


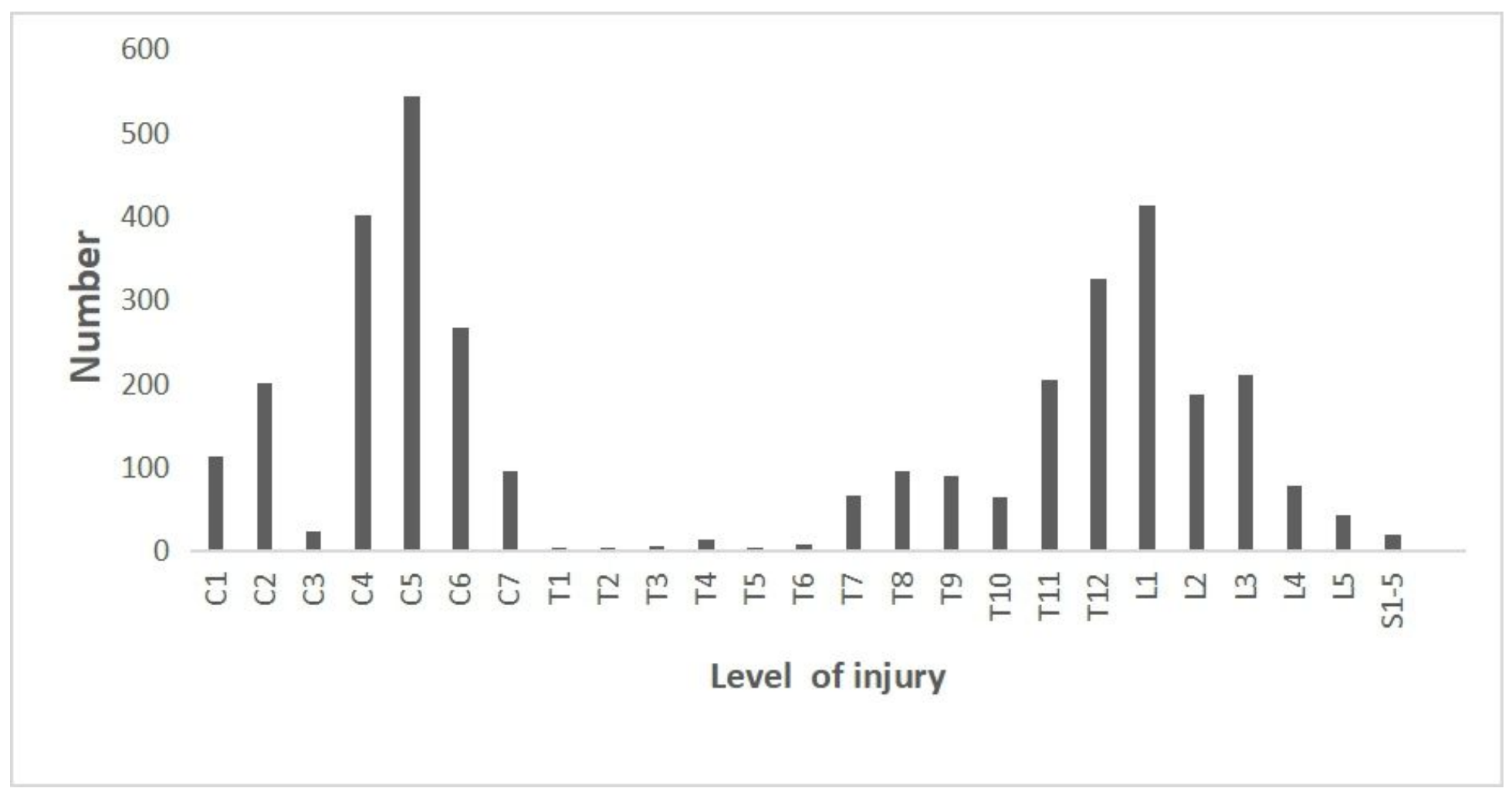

Figure 2

Distribution of spine level injuries for $\mathrm{SCl}$ patients by the severity of injury 